\title{
ARCHITECTURAL DRAWING AS A MEDIUM OF COMMUNICATION, EDUCATION AND INTERACTION WITH THE COMMUNITY; CASE STUDY PRISHTINA, KOSOVO
}

\author{
${ }^{1}$ Arta JAKUPI, ${ }^{2}$ Teuta JASHARI-KAJTAZI \\ ${ }^{1,2}$ Department of Architecture, Faculty of Civil Engineering and Architecture \\ University of Prishtina, Bregu i Diellit p.n, Prishtina, Kosovo \\ e-mail: ${ }^{1}$ arta.jakupi@uni-pr.edu, ${ }^{2}$ teuta.kajtazi@uni-pr.edu
}

Received 14 July 2017; accepted 2 September 2017

\begin{abstract}
This study aims at revealing the power of architectural representation through drawing on community engagement and development during the design process. Considering the drawings as a medium for obtaining knowledge and using them as a means of communication, for the generation and development of designs together with the community, the idea behind was to understand if the representation and communication approach can trigger the community participation, engagement and education on understanding and creating their future city.

For the accomplishment of this research the mixed methodology was used, quantitative methods with tools such as questionnaires and mental maps, whilst qualitative method employed interviews, empirical studies and observation on the ground.

The use of a certain architectural representation as a communication means, that could be attractive and well understood by the community, can encourage public engagement, discussion and generation of ideas, by this ensuring their collaboration during the planning and design process, as active participants and well-informed citizens.
\end{abstract}

Keywords: Architectural drawings and representation, Mental map, Visualization, Community engagement and development, City planning

\section{Introduction}

'Designing and making is like having a quiet sort of game, and that game is played through drawing' [1].

This paper discusses architectural drawings and visual language as a medium for communicating, educating (understanding architecture) and engaging the citizens on public designs. The emphasis of the discussion will be on peculiarly 'central' role of 
drawing as the medium of knowledge and understanding, and hence power, in architecture [2, pp. 101].

As professional architects, many situations were noticed where the clients or the parties involved within a project design, do not understand architectural drawings. The misreading of the drawings leads to the misunderstanding of the concept by deepening the problems in communication, consequently producing undesired design. This problem is of another magnitude when the parties or stakeholders, which ought to be involved, in fact need to be invited or attracted on voluntary bases. The design of public architectural-urban plans is an example, where the engagement of the community during the design process, is mandatory. In these cases, the doubt or fear of the participants, for not being able to understand architectural drawings or what is being presented to them, is an added reason not to join or participate during the design process. This study tries to understand if the representation mode can trigger the community participation/engagement and education of the citizens in understanding and creating their future city.

\section{The outline of the problem}

'The true city design-dealing directly with the ongoing sensed environment of the city, in collaboration with the people who sense it, hardly exists today' [3], a statement made by Lynch in 1990, and still actual in today Prishtina, as the capital city of Kosovo. After the end of the conflict in 1999, there have been many disputes over the International Community reconstruction; if it has been delivered in the right manner and if it could have been realized differently. Whatever the case, the Post Conflict Reconstruction Framework [4] indicates that the result of this process is the community takes charge over the situation, by fostering sustainable growth and development [5]. Sustainability should be a bottom-up process, by ensuring the community engagement in state development processes, something, which majority of Kosovo citizen's lack. The non-engagement of the community in Kosovo can be argued differently by different stances, including the result of cultural and traditional aspects, as well as the fact that anything that was of public realm, in fact, belonged to the government, therefore the citizens did not feel as rightful stakeholders.

Whichever the reason, the lack of community engagement should be perceived as a serious problem. For that purpose, as case study was taken the capital city of Kosovo, where the planning institutions are more active and there is a concentration of conglomerate population coming or moving to and from other cities and villages [6]. The planning institutions in Prishtina do try to promote community design, but the reality of public discussion showcase situation with a very small number of participants or none. Authors have been in several public discussions about the design of public spaces, and in some cases the discussions were not held due to the absence of the community. It must be noted that this is evident within projects which ought to belong to the public, like public spaces, parks, public buildings etc., where different is the case if the individual interest is affected and there is a debate and participation from all the involved stakeholders.

All the above-mentioned aspects can contribute to the creation of the community non-engagement problem, or with the possibility to have more serious implications. For 
that reason, the aim of this research was to tackle a different aspect which is not of this magnitude, but can produce great results trying to challenge the problem not from the same situation as it was created. The aim was to find a specific medium that could be attractive, well understood and encourage discussion. Starting from these observations, the following research questions derived:

- What kind of means can be used for triggering the public participation in urbanarchitectural designs?

- What kind of visual language can be used for the community to understand and get related with the urban-architectural designs?

Initially, the study began as part of the postdoctoral research at Vienna University of Technology (VUT) Institute for Art and Design, whilst the completion continued in Prishtina, with the group of students from the University of Prishtina, Faculty of Architecture, with the aim of understanding adequate visual communication that could attract and engage citizens. It is to be considered that the knowledge and understanding of the visual language should be acquired by analyzing examples through drawing; therefore, primarily the study began with the individual mind maps and questionnaires, by continuing with the development of large scale map on the street and creating one 'collective' mind map of the future city.

\section{Literature review}

In the literature of architecture, drawing is presented as being used in three distinct ways: as a medium for communication, as a medium for design, and as a medium for analysis [2, pp. 102].

This research is concerned with the aspects of the drawings represented on the mental sketch map as an ability to imagine the spatial world, moreover as an effort to define perceptive maps and the variances among the citizen's perception of the actual conditions of an urban area and their perception about the future city. People have some kind of internal model of a physical space, and that the spatial knowledge is 'map-like' [7, pp. 56]. The most noticeable study of mental maps was given by Kevin Lynch in 'The Image of the City', where he discovered the five components of the city; nodes, edges, districts, paths and landmarks [8]. The same components were under intention to be identified within the city of Prishtina, by obtaining the information from the citizens mind map. The reason why the mental map was chosen is to try and understand, firstly, how the citizens read and what do them percept in the city. The mental maps would reveal a building or place, which the citizens would recall due to the distinctiveness of its physical form; its visibility to him as he travels around the city; its role as a setting for personal activities, use and other behavior; and the inferences he makes about its cultural significance to the population at large [9, pp. 135]. Same as Apple-yard stated, that a good predictive formula would give the planner and designer a vocabulary of urban attributes, which can be used in several ways [9, pp. 155]. According to Jiang, in his study about the image of the city, there are two fundamental issues surrounding research on the image of the city, it is the city's external and internal representations [10]. Therefore, this study deals with the internal 
representation, regarding how the city is represented in human minds internally, whilst the external representation is the city itself, its external to human minds [10]. In this study, the focus is also on the drawing of the mental map as a manual-intellectual activity. Where some sorts of knowledge and understanding can be seen to reside in a drawing as an artifact or object of art, and hence be 'readable' in one way or another, but here the enquiry considers the knowledge and understanding 'inhabiting' the performative interchange that is under-way while a mind is engaged in drawing [2, pp. 101].

Jiang develops an argument that the image of the city arises from the underlying scaling of city artifacts or locations, and states that, where the scaling refers to the fact that, in an image-able city (a city that can easily be imaged in human minds), small city artifacts are far more common than large ones; or, alternatively, low-density locations are far more common than high-density locations. Eventually, those extremely unique and vital artifacts make up the image of the city [10, pp. 1552].

There is a lot of information included within the mental maps, on how people recognize the environment. Different kinds of observers, use and know the city differently. There is some knowledge and significance in each and one about the surroundings living in and must navigate through. It is about the personal experience, what is important to the subject and how it is going to be represented [7, pp. 61]. The right medium of communication and presentation would give space and possibility to everyone to be expressed freely and vividly, as to generate and develop adequate designs.

\section{Methodology}

The used methodology employed mixed methods, where, both of the methods were inter-related with one another and occurring on alteration. Primarily involving the quantitative tools, as questionaries' together with sketch maps, whilst, observation, interviews, as qualitative methods, were applied during the survey. The derivative of the individual sketch maps was the big collective map, made on the ground, attained through drawings, discussions and interviews. The employed mental map is drawn from observation rather than from exact measurements and represented the main features of an area, which at the same time is the simplest technique, using mazes and drawing sketch maps [7, pp. 54]. This technique, established by Lynch in 1960 allowed us to collect much comprehensive information about citizen's mental maps [8]. According to many researchers the major disadvantage with this method, is that the sketch maps of different individuals differs not only because their mental maps vary but also because of variation in drawing ability, the perspective from which the map has been drawn, the scale and the type of map [7, pp. 54], opposite to this study, where these disadvantages are considered as the main feature of the analysis. The disparity, the similarity, the nature of the inaccuracies and mistakes of the mental maps, are itself interesting and worth analyzing.

The survey was accomplished by 80 students. Each group of students (five per group) had to collect 50 sample drawings from different categories of citizens. The primary categorization was done by Age, while the active population was further 
categorized by professions, e.g. Parents (moms with babies and toddlers);children 5-12 years; teen 13-18 years; young adults 18-21 years; adults by profession; academics (teachers, professors..); culture ( art, artists, singers etc.); sport; medical; Industry + Science (economist, lawyer, library, engineer, biology, botanic, physics etc.); public services (firefighters, police, military etc.); transportation (taxi driver, bus driver, pilot, etc.) technology ( programmers, web designers, graphic designers, architect, const. engineer, etc.); politics; jobless; homeless; handicap; elderly. The citizens were asked to draw places within the city of Prishtina (Fig. I), places that were important to them or were part of their daily activity (one of their typical day).

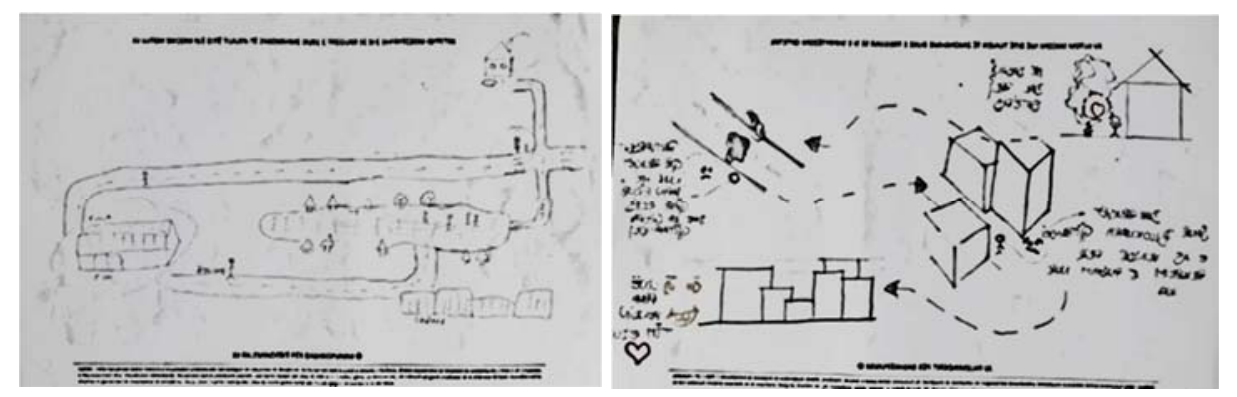

Fig. 1. The mental maps. (Source: collected by the students)

The additional at the end was to improve the drawing with some extra features that they aspire to see in the future, within their daily routine. The citizens were provided with pen and paper (free to draw or write). The individual mind maps helped understand the differences and the consistencies of the citizens, with the aim of producing a collective familiar representation of the city. The idea was to produce a big scale collective mind map, by laying down the main city attributes on the ground (main square of Prishtina), landmarks including the National and University Library [11], so that citizens can easily navigate through the map by walking on it. The topic was the future of Prishtina, and the citizens had to fill the empty map of Prishtina, by leaving only the main urban attributes (derivative from the individual mind map of the citizens). The intension was to give a useful snapshot of the perceived quality of the prominent elements in the city, and put the information in a form easily communicated to the public so that they point to recommendations and controls for visual quality [10].

\section{Analysis and results}

Sketch maps may not consistently point out the detail of persons mental map, it is and in coherence with the individual's drawing ability. Analyzing sketch maps may be difficult due to variations in the perspective from which they are drawn, the scale and the orientation of the paper chosen by the participants may be misleading. Participant's maps are disproportionate; they tend to exaggerate the size of places that they know well or prefer. They tend to overestimate the size of their own neighborhoods compared to other districts of the city, as Seibert and Anooshian, stated at their study, some of the 
participants omitted from their sketch maps areas or landmarks that they did not like [7, pp. 56].

The drawings of the mental maps, in this study, were perceived as an innocent activity, with no serious implications. The participants felt amused and competent on the information they were providing. Intentionally the first questions of the individual maps were done about the participants' daily activity, something that they could easily provide, with no right and wrong answers, and always having something to say. The intention was to trigger the citizens on providing something easy, for which they felt confident, and with easiness would agree to be part of the survey.

The tailoring of the questions was the biggest challenge. Since there was not any specific architectural or urban design, to work on (except for the fact to be able to understand the communication manner and the participation cause), something to be more easily understood and which involves a greater number of population was developed, including a bigger sample of surveys, opinions and different categories of population. Architectural and urban designs are about the future projections; therefore we requested a future projection of the city. When testing the pilot sketch map, for the individual mind maps, it is understood that this question was too broad and did put pressure on the participant, mainly, due to the doubts of not performing well and cleverly on this task. As a result, questions that are more of a narrative logic came up, so that the participant gets familiar and in tune with the process. Therefore, only after the first drawing is finished, the question about the future projection is introduced to the participant. Mental maps were distributed randomly within randomly chosen neighborhoods of Prishtina (Fig. 2). There were 756 mental maps collected. The results from the analyses of the individual mind maps, identified most common city elements (main buildings, parks, squares, routes etc.), aside from their homes and workplaces, which were the main components of their daily routine, but different for each participant, which helped later in the process, to construct the big collective mental map. The manner of visualization revealed the simplest and the most understandable way of representation that we needed to test it out on another map, as we named it as a 'collective mental map'.

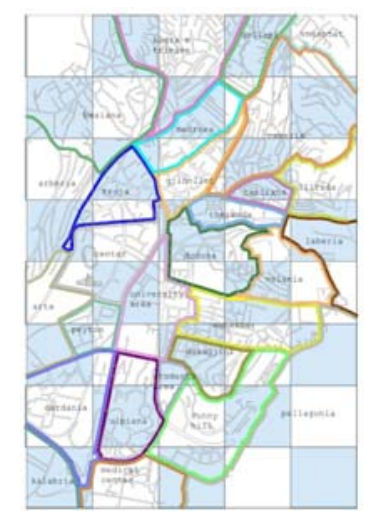

Fig. 2. The random distribution of the mental maps, in various Prishtina neighborhoods (Source: Authors plot) 
The layout of the collective mental map was generative from the results of the individual maps. The emphasized was only on the main streets and the main city elements (buildings, parks, squares) (Fig. 3). Both features were the most represented on individual mental maps, the first were used as a logical connection for different points, while the second helped the participants navigate through the city. Since most of the participants had trouble connecting to the reality from the small paper maps, the possibility of constructing a bigger scale map was considered, where citizens could walk and experience the projection (Fig. 4).

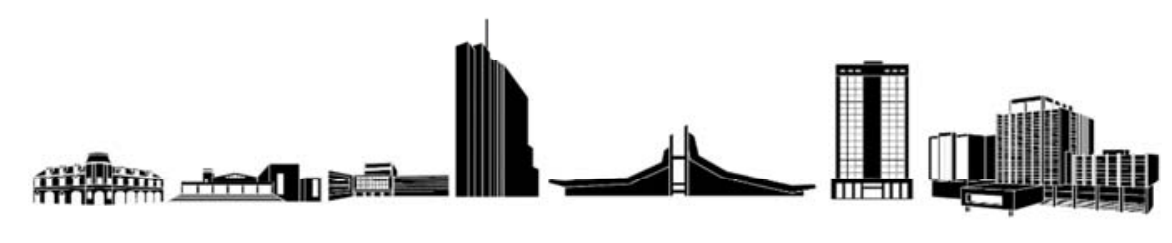

Fig. 3. The main city elements identified during the individual mental map and drawn in the 'collective map' (Source: Martina Culaj plot)
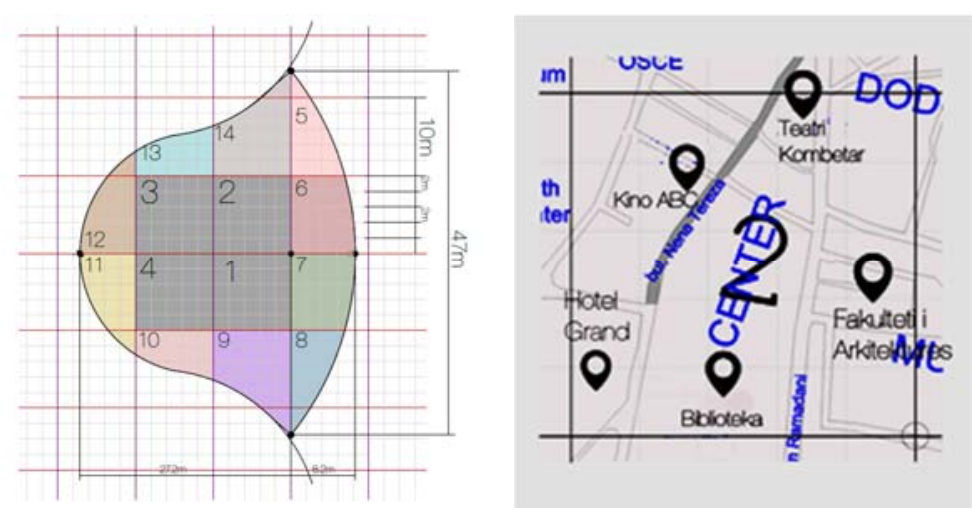

Fig. 4. The sketch of the 'collective map', drawn in $\mathrm{P}=1: 5$ in the 'Skenderbeu' square-Prishtina city center (Source: Dea Luma plot)

The collective map did coordinate urban form and visibility with the active experience of the inhabitant, so that the latter could find his way more clearly around the city.

The map with chalk on the ground was drawn or illustrated, so that, the citizens could see the representativeness of the drawings with its errors and exquisiteness, and felt free to contribute in the same manner (Fig. 5). They started to draw spontaneously with the intention of only providing information, but later realized that drawing was helping them to understand relationships and to make relationships, garnering another kind of wisdom of place and people [12, pp. 34]. 


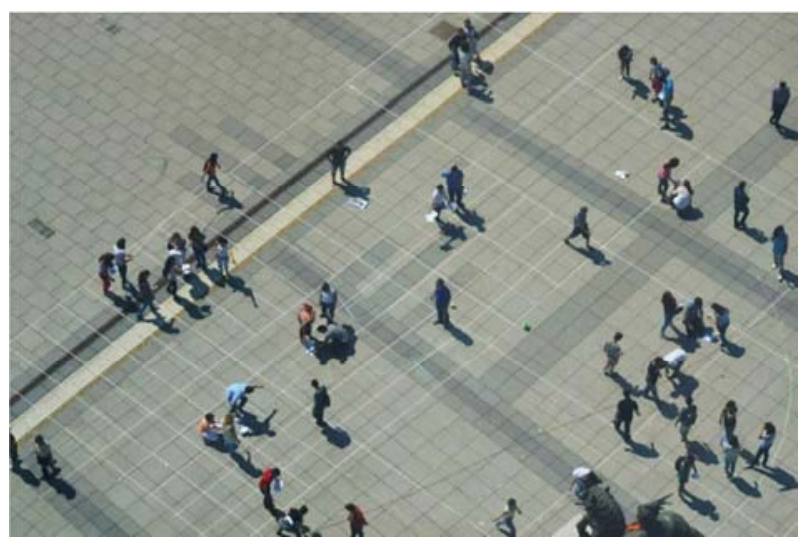

Fig. 5. The realization of 'collective map', $\mathrm{P}=1: 5$ in the 'Skenderbeu' square-Prishtina (photo: Dea Luma and Festim Halimi)

There was a big number of people involved, some of the citizens/by passers were invited to join, while some were curious and joined by themselves. The participants, despite the fact they were drawing, it turned out to have compassionate involvement with the place and the people, consequently producing a very creative map, full of inventive and interesting features (Fig. O).
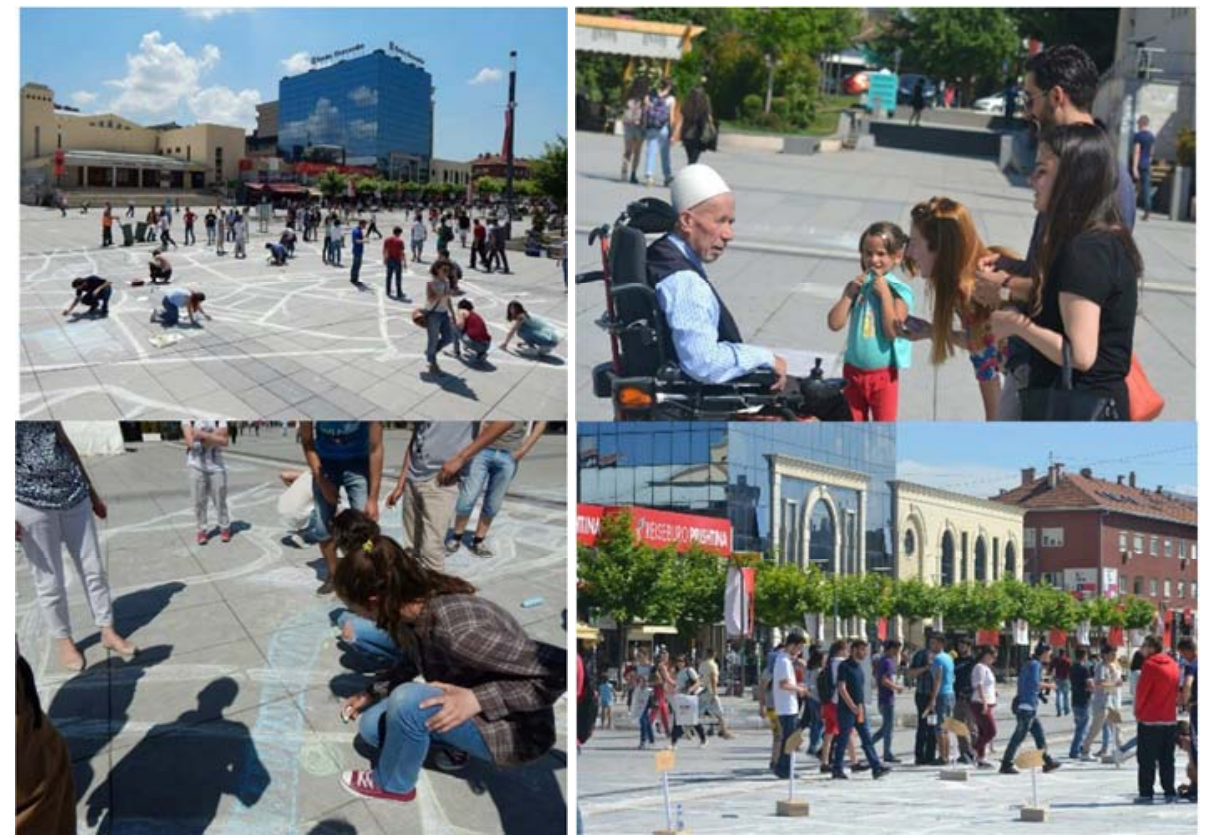

Fig. 6. The 'collective map', 'Skenderbeu' square-Prishtina (photo: Dea Luma and Festim Halimi) 
It is worth noting that the obtained information can be a subject to a further analysis and studies, but within this paper the focus is only on the visual language and the ability to attract the citizens to take part in public designs and discussions.

It is not sure if this study can be replicable with the same easiness on cases, which deal with more serious implications, as well as when attained by the city officials'. Universities undertakings or events are perceived as neutral activities, especially when the research is being performed by students, who are perceived as category that ought to be helped, especially for their schoolwork.

\section{Conclusion}

The purpose in doing the mental sketch maps was not to produce just drawings but to gain knowledge and understanding that could be used in the interpretation of how the citizens contemplate.

Through mental map, the visual language is developed, while the drawings have the intellectual structure, where mind is not simply receptive, but becomes an involved actor.

Therefore, it can be concluded that drawing, in this research, was important for visualizing, understanding, educating and making interactions, including:

- Visualizing the ideas and projections, as an intellectual endeavor.

- Gaining understandings of the conceptions and relationships.

- Educating the citizens, the way architecture is represented and regarded.

- Useful for making interactions, as for being able to gather participants and anticipate with them.

The entire content was coordinated, including visualization, and action with the community, which was significant to create a more meaningful design. The product was the collective participatory drawing, of the city, time and people.

The use of the architectural representation (drawing) as a communication means, that could be attractive and well understood by the community, can encourage public engagement, discussion and generation of ideas, by this ensuring their collaboration during the planning and design process, as active participants and well-informed citizens.

\section{Acknowledgment}

This study is a derivative of Arta Jakupi post-doctoral research done at the TUV, Institute for Art and Design, under the mentorship of Otto Mittmansburger and Christine Hohenbuchler, financed by the OEAD. It was realized at the University of Prishtina, within the subject of Architectural Representation, in collaboration with Teuta Jashari-Kajtazi and the help of the first year students (generation 2014/15: A. Rama, A. Jusufi, A. Vitija, A. Lajçi, A. Dervishaj, A. Krasniqi, A. Rahimi, A. Omer, A. Zabeli, A. Rexhepi, A. Hysenaj, A. Rexhepi, P. Morina, A. Grdellaj, A. Krasniqi, A. Nikqi, A. Ajdrapasic, A. Zullufi, A. Nebiu, A. Kololli, A. Berisha, A. Rexhepi, H. Maqastena, B. 
Geci, A. Rogova, A. Blakaj, A. Blakaj, B. Retkoceri, B. Talla, B. Bislimi, B. Hyseni, B. Boshnjaku, U. Sadikaj, B. Krasniqi, B. Mulliqi, D. Shabani, D. Kurtaj, D. Sylhasi, D. Shabani, D. Demiri, D. Berisha, E. Kabashi , E. Kryeziu, E. Maxhuni, E. Saliji, E. Bojku, E. Avdiu, E. Przhella, E. Mehmeti, P. Haxhaj, F. Gruda, F. Gashi, G. Salihu, H. Ziberi, A. Krasniqi, J. Osmanaj, L. Ramadani, L. Duraku, L. Hysenaj, L. Hyseni, M. Sharku N. Merovci, Nj. Krasniqi, P. Mikullovci, P. Hyseni, B. Mavraj, F. Haliti, R. Jetullahu, R. Hoxha, R. Kollqaku, Rr. Tanushi, Rr. Pozhegu, Sh. Bytyçi, Sh. Ajdari Sh. Zeqiraj, S. Sadrija, T. Imeri, D. Tashi T. Hoxha, V. Hamza, V. Shporta, Xh. Mujedini, Y. Haxhikadrija, Z. Sezallari, Z. Maliqi.) of the University of Prishtina-Faculty of Civil Engineering and Architecture.

\section{References}

[1] Robbins E. Why architects draw, The MIT Press, 1997

[2] Unwin S. Analyzing architecture through drawing, Building Research \&Information, Vol. 35, No. 1, 2007, pp 101-110.

[3] Lynch K. Reconsidering the image of the city, In T. Banerjee and M. Southworth, Eds, City Sense and City Design: Writings and projects of KevinLynch, Cambridge, MA, The MIT Press, 1990.

[4] Hasic T. Reconstruction planning in post conflict zones in Bosnia and Herzegovina and the international community, Doctoral Thesis, Royal Institute of Technology, Stockholm, Sweden, 2004.

[5] Jakupi A. The effect of the international organizations on the post conflict urban development, Lambert, Saarbrucken, 2013.

[6] Ahmeti P., Dalipi I., Basha A., Kistelegdi I. Current heating energy demand by the residential sector in city Prishtina based on the main resources, Pollack Periodica, Vol. 12, No. 1, 2017, pp. 147-158.

[7] Imania F., Tabaeian M. Recreating mental image with the aid of cognitive maps and its role in environmental perception, Procedia - Social and Behavioral Sciences, Vol. 32, 2012, pp. 53-62.

[8] Lynch K. The image of the city, Cambridge, MA, MIT Press, 1960

[9] Appleyard D. Why buildings are known, A predictive tool for architects and planners, environment and behavior, Sage Journals, Vol. 1, No. 2, 1969, pp. 131-156.

[10] Jiang B. The image of the city out of the underlying scaling of city artifacts or locations, Annals of the Association of American Geographers, Vol. 103 , No. 6, 2013, pp. 1552-1566.

[11] Jashari-Kajtazi T. Architectural interpretation of the National and University Library in Prishtina; the influence in its surroundings, Pollack Periodica, Vol. 12, No. 1, 2017, pp. 171-180.

[12] Nasar J. The evaluative image of the city, Journal of the American Planning Association, Vol. 56, No. 1, 1990, pp. 41-53. 